\title{
A Proposal for a Personal Branding Support Service in Social Media Times
}

\author{
Yoshihiro Kawano $^{1}$ and Yuka $\mathrm{Obu}^{2}$
}

Social media such as Twitter and Facebook have become popular. In the age of social media, many people have become more active online. For example, about half of all global active Internet users are on Facebook (Perry 2012). Personal branding is a very important strategy to build on an individual's strengths, and this kind of branding is expected to contribute to selfactualization. Therefore, the presence of mentors who advise users to discover their own strong points for self-actualization is necessary. In this paper, we propose a personal branding support service, Mentors, which connects mentors and mentees. The core concept is: "Everyone has the face of both a mentor and mentee." The key function is sharing stages of selfanalysis in human life design: Determining value, creating a mission, and forming a strategy. From this function, a good match between a mentor and mentee can be found. The program aims to improve human life by understanding the client's strengths and using social media effectively. Future work includes launching Mentors and evaluating its service.

Keywords: Social media, Personal branding, Self-actualization, Mentor

\section{Introduction}

Today, job hunting activities are diversified. For example, students usually get jobs using various methods, i.e., through internships, social media, and starting up their own ventures. Moreover, promoting these activities, belonging to communities and creating interpersonal networks are important. To thrive in such social circumstances, people need to actively emphasize their individual strong points.

Recently, the use of social media, including Twitter, Facebook, and LinkedIn, has become widespread. In the age of social media, many people have become more active in their online activities. For example, about half of all global active Internet users are on Facebook (Perry 2012). Personal branding (Peters 1997) is a very important strategy for capitalizing on individual strong points (Ohmoto 2011). We define personal branding as an activity for using an individual's strong points and building one's own brand. In addition, it provides opportunities to establish a good interpersonal network and obtain information that helps build careers and businesses. We maintain that personal branding has two sides, namely, inside and outside branding. Inside branding is the clarification of one's strong points by self-analysis, and outside branding involves presenting these strengths as a specialty. Personal branding is expected to contribute to self-actualization. Therefore, the presence of mentors who advise mentees on how to find their own strong points for self-actualization is needed. Social media literacy is also one essential skill for personal branding using social media. This form of liter-

\footnotetext{
${ }^{1}$ Assistant Professor, Department of Informatics, Tokyo University of Information Sciences, Chiba, Japan.

Contact information: ykawano@rsch.tuis.ac.jp

${ }^{2}$ Freelance researcher. Contact information: yuka.obu@gmail.com
} 
acy is the skill of disclosing suitable information, as well transmission and communication with others using social media.

Personal branding may also play a role in career education for university students. Today, graduating students are faced with major decisions involving career choices, diverse values and ways of life, self-analysis, humane growth, and contributions to society. Emphasizing their strengths and demonstrating their potential contributions have become important tasks in their search for employment after finishing their university studies.

We are studying personal branding for students through the practical use of social media (Kawano 2012, 2013). This is because several companies use social media to recruit students who are highly sensitive to information technology-related issues and who have excellent communication skills. Our goal is to create an education and training scheme to enable students to design and build a life for themselves using personal branding. However, this process takes a great deal of time before results appear. We propose a personal branding support service, Mentors, which aims to improve human life by understanding each mentee's strong points and combine such strengths with the effective use of social media.

\section{Related Work}

Recently, the employment rate for students in Japan is very low as a result of the conditions caused by the global economic depression and also as a result of changes in the goals of major corporations. Data from the Japan Center for Economic Research in 2011 suggests that the increase in the early unemployment rate (less than three years) is caused by a mismatch between new employees and companies (Japan Center for Economic Research 2011). In modern times, people are required to capitalize on their individual strong points to thrive in society.

The Ministry of Education reported in 2011 on how career education for students has attracted attention at many universities. There have been many pieces of research on career design in the field of psychology (Hanzawa 2011), including mentoring, coaching, development psychology, and motivation (Eccles and Wigfield 1985, 2002), self-affirmation and self-efficacy (Lent, et al. 2002). In Hanzawa (2011), the relationship between students' learning and career problem has been reported. There is a consciousness that students want to relate what they learned in university with their future careers. The necessity for research concerning careers from the perspective of student personal development through learning in the university is described. In Lent (2002), social cognitive career theory (SCCT) is proposed to foster self-efficacy. It is supposed that people's "cognition" plays an important role in career development in or decision-making about a career. According to this theory, self-efficacy (beliefs about our abilities to succeed), outcome expectations (beliefs about the outcome of performing particular behaviors) and personal goals (the determination to engage in a particular activity or to effect a particular outcome) are three important building blocks for career development. In particular, prior accomplishments in performance contribute to increases in motivation for self-efficacy. Eccles, et al. (1985) proposed an expectancy-value model of achievement-related choices, and explored the nature of student motivation and its relationship to achievement. In this model, choices are assumed to be influenced by both negative and positive task characteristics. As noted in Eccles, et al. (2002), four components in task value include attainment value, intrinsic value, utility value, and cost. The final item, cost, is a critical component of value. Cost is conceptualized in terms of the negative aspects of engaging in the task such as performance anxiety and fear of both failure and success.

From these researches, we confirmed that the learning in university had a lot of influence on career development, and that improvement of self-affirmation of students was important on the career education. In order to improve the self-affirmation, it is important for 
each student to clarify self-efficacy, outcome expectations, and personal goals (on the theory of Lent's research), and Eccles indicates checking its achievement is important. Therefore, in this research, we made study to define self-efficacy, outcome expectations, and personal goals, and planned to develop the system to check the achievement of goals on human life design for students.

In human life design, the components of self-analysis - that is, value (what you feel is most valuable in life), mission (the goal which you truly want to achieve), and strategy (the "to-do list" to improve "values" and to achieve your mission) - are useful for selfactualization (Tsubota 2008). These three components are intrinsically inherent in the abovementioned researches. And, we assume that student will determine their own values, mission, and strategies in the process of determining their life design and in improving their motivation and chance of success. Hence, we decided to adopt values, missions, and strategies to define self-efficacy, outcome expectations, and personal goals of students in our system and our career education. However, many students do not deeply consider their own life design. For students to execute their life design, hard work, friendly relationships, and rivalry by disclosure of their plan is required. Our assumption is that sharing values, missions, and strategies contributes to each student's individual process of clarifying the type of person that s/he truly wants to become. This is an effect through friendly competition for their life choices. Self-actualization for students could be more easily attained at this point in their lives.

\section{Personal Branding for Students}

Personal branding is one tool used in the process of self-actualization. Having selfaffirmation and self-efficacy are the first steps in personal branding. We consider social media to be an efficient tool for personal branding because it enables young individuals to improve their self-affirmation and self-efficacy.

To assess the actual situation facing high-school students and their educational environment, we conducted surveys targeted at both high-school students and teachers in one high school with the official cooperation of the Tokyo University of Information Sciences. The survey consisted of a lecture section and a survey section. The number of student participants was 21 , and the number of teacher participants was 29 . We conducted the lectures and surveys on August 1, 2012 for students and on August 9, 2012 for teachers. In order to provide basic knowledge concerning particular issues, we gave lectures to high-school students and junior-high/high-school teachers about social media and personal branding (Kawano 2013). In this lecture, we investigated and demonstrated the relationship between self-affirmation and the practical use of social media. The four main content points covered in the lectures were as follows:

(1) Basic social-media use and its practical utilization for retrieval of information;

(2) Social media literacy: Well-balanced information disclosure and communication;

(3) Creation and maintenance of positive relationships with society (e.g. participation in events and making contact connections); and

(4) Discovery of the effective use of social media for personal branding through active discussions among educators and students.

These four components involve essential social media skills. Self-affirmation and selfefficacy are fostered through obtaining these skills and using social media. Currently, social media tools are closely connected with individual application and utilization. From the above, we believe that the practical use of social media is connected to students' future plans. Hence, 
applying efficient social-media literacy skills improves personal branding efforts, and this in turns leads to each individual student's self-actualization.

For the student-oriented lecture, the 21 student participants were divided into four groups. Each group consisted of 4 to 5 students, and students discussed the following items:

- Individual strong points;

- Social media literacy;

- Personal branding; and

- Discussions about the above themes.

For the educator-oriented lecture, the 29 teacher participants were divided into six groups. Each group consisted of 4 to 6 teachers, and teachers discussed following items:

- Individual strong points;

- Social media literacy;

- Information education in the school;

- Personal branding for high-school students; and

- Discussions about the above themes.

\section{Survey Results}

In the student-oriented lecture, we conducted a survey aimed at students concerning their self-identified strengths, as such strong points relate to self-affirmation and self-efficacy. Therefore, we determined that self-identification of their strengths contributes strongly to self-actualization.

Based on that hypothesis, we designed a survey that would allow students to freely answer the question: "What are your strengths?" We analyzed this qualitative data and classified students according to the recognition level of their strengths (Figure 1), surmising that the recognition level of their strengths contributes to self-actualization. On a scale, "Level 0" was considered to be without recognition and "Level 4" was deemed the highest level of recognition. Students who were classified as Level 4 are able to use their strengths for actual activity.

Our findings show that about $70 \%$ of the students recognize their strengths (based on an aggregate total of Levels 2, 3, and 4). However, we found that none of the students were classified as Level 4. For personal branding, it is necessary to use an individual's strengths for actual activity, and thus, in order to increase the number of students who could attain Level 4, periodical lectures and progress observations are required.

Concrete answers to the classification of strengths included: Persistence ( 5 responses), creativity ( 5 responses), confidence (4 responses), imagination (3 responses), curiosity (3 responses), and communication skills (3 responses). In addition, other responses included language skills, interpersonal network, sense of commitment, and leadership. 


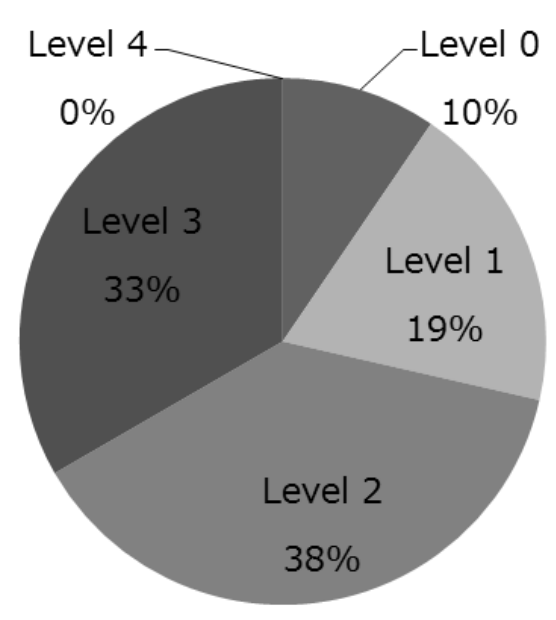

Next, we asked students whether they can put personal branding into practice. We allowed free-form responses to the question: "What are the merits for high-school students to do "personal branding'?" One-third of the students responded that they can put personal branding into practice, and two-thirds of the students responded that they could do so conditionally. In addition, we obtained the following comments from high-school students concerning the merits of personal branding:

- Easy to be recognized from the society;

- Easy to retrieve opinions from young people;

- They can know about society from youth;

- Easy to construct interpersonal network; and

- Useful for retrieval of information.

Although many students appear to understand the advantages of personal branding, including recognition from society, sympathy, and the development of their interpersonal networks, it appeared difficult for them to relate these concepts to actual activity.

In the lecture aimed at educators, their strengths as teachers in supporting the students were also surveyed. We allowed free-form responses to the question: "What are your strengths?" We classified the responses in a similar manner to the student responses noted earlier. Table 1 shows the responses from educators concerning their strengths. From Table 1, we could confirm that educators use strengths for education.

Next, we investigated how educators could assist students in putting personal branding into action. We allowed free-form responses to the question: "How can a teacher assist students in doing 'personal branding'?" The responses were as follows:

- $\quad$ Actual use of Twitter, Facebook;

- Introduction of cases about social media literacy;

- Observation of the students and interposition;

- $\quad$ Training in sociality; 
- Improvements in writing skills;

- Instruction in managing personal information;

- Responsibility for information;

- Encouragement of opportunities to reflect upon oneself;

- Moral and literacy education concerning information; and

- Instruction in handling emerging issues.

Table 1 Educator strengths based on classified free-form answers (Educators, $N=29$ )

\begin{tabular}{lc}
\hline \multicolumn{1}{c}{ Strengths } & N \\
\hline Special knowledge about subject area & 21 \\
Interpersonal network & 10 \\
Student and career guidance & 8 \\
Social credibility & 7 \\
Sense of commitment & 7 \\
Youthfulness & 6 \\
Communication skills & 5 \\
Industry experience & 1 \\
\hline Note: Numbers do not add up to 29 because multiple responses \\
were allowed.
\end{tabular}

Many educators responded that they can perform social training as branding support for students (e.g. interposition of their activities, improvements in writing skills, and offering opportunities to reflect on oneself). For students, starting personal branding activities at an early age is very important in building interpersonal networks because constructing such networks takes a long time. There are many intrepid educators who conduct student guidance, and educators can be a mentor for students. Moreover, we were able to confirm that lectures about social media literacy and personal branding are necessary for the students. Personal branding for students is a very important issue in designing their lives.

\section{What is a Mentor?}

A mentor is a good adviser or coach who can give pertinent advice to the mentee; they are also very understanding and sympathetic. In this research, mentees are students who have not yet clarified the type of person whom they truly want to become, or students whose activities are not self-directive. The roles of the mentor for the mentee are as follows:

(1) To encourage the mentee to obtain awareness of self-actualization;

(2) To become a role model for the mentee; and

(3) To share his/her philosophy.

Professors, university careers advisors, or other students may become mentors. The number of mentors for each mentee is unlimited. One student can be a mentor for another student as well. The aim of this study is for students to decide their goals by themselves through discussions with their mentors and promote themselves through self-directive activities. 


\section{Design Concept of a Self-actualization Support Service}

The above discussion forms the basis for a support service for personal branding undertaken by university students. In personal branding, it is very important to use the strengths of the individual. Mentors who can advise mentees on how to discover their own strong points are necessary. Therefore, we propose a personal branding support service called Mentors.

Using this service promotes self-actualization by the mentee. The concept of Mentors is "Everyone has the face of both a mentor and mentee." The most featured function is the capability to share components of self-analysis in how people design their lives, i.e., values, missions, and strategies. These concepts are defined as follows:

(1) Values: What you feel is most valuable in life, e.g. to be helpful to people, to enjoy life, or to love people.

(2) Mission: The goal which you truly want to achieve, e.g. to get a good job, to find friends who can work hard, or to discover your life goals.

(3) Strategies: The "to-do list" to improve values and to achieve your mission, e.g. to obtain information technology credentials, to participate in many seminars, or to create a movie.

The growth process that is used to clarify values, mission, and strategies is shown in Figure 2. There are five steps involved in providing mentoring for mentees.

Step 1: Discover values

Step 2: Set up mission

Step 3: Discuss strategies

Step 4: Evaluate mission achievement

Step 5: Repeat from Step 1

Each mentee needs to decide on Steps 1 and 2 by themselves because values and mission are internal issues for each person. The mission involves goals to be set and accomplished within certain periods of time. In Step 3, the mentor and mentee discuss which strategies can be utilized to realize the mentee's mission. Strategies can be classified into two types, that is, input strategies involving study, interpersonal networking, and development of a personal philosophy, as well as output strategies involving prototyping, writing, and creation. In Step 4, mentees evaluate the degree of mission achievement at the end of the term by themselves. Finally, the mentee repeats the process from Step 1. Through these steps, the person that the mentee truly wants to become is clarified and, moreover, matching the mentor and mentee is promoted. Mentors aims to improve human life by understanding the mentee's strengths and using social media effectively.

A conceptual overview of Mentors is shown in Figure 3. The mentee determines and sets up values and his/her mission, posts the strategies, and check items off a to-do list. The mentor posts strategies and gives advice to the mentee. Through the above steps, Mentors matches the mentor and the mentee. Mentors is similar to Forkwell and Wantedly. Forkwell (https://forkwell.com/) is a skill-based networking site for engineers and creators, and functions similarly to LinkedIn, albeit aimed for engineering professionals. They can create a personal brand with Forkwell, and there is a mechanism for having their own skills evaluated from other people. Wantedly (https://www.wantedly.com/) is a matching service for meeting others with the same purpose (project members, social friends, etc.).

Mentors specializes in finding a suitable mentor for mentees. Mentors will be developed as a Facebook-based web application because Facebook's social graph network is based 
on an actual human network. Mentors aims to improve human life by deepening understanding of a mentee's strengths and using social media effectively.

\section{Figure 2 Growth process in values, mission, and strategies}

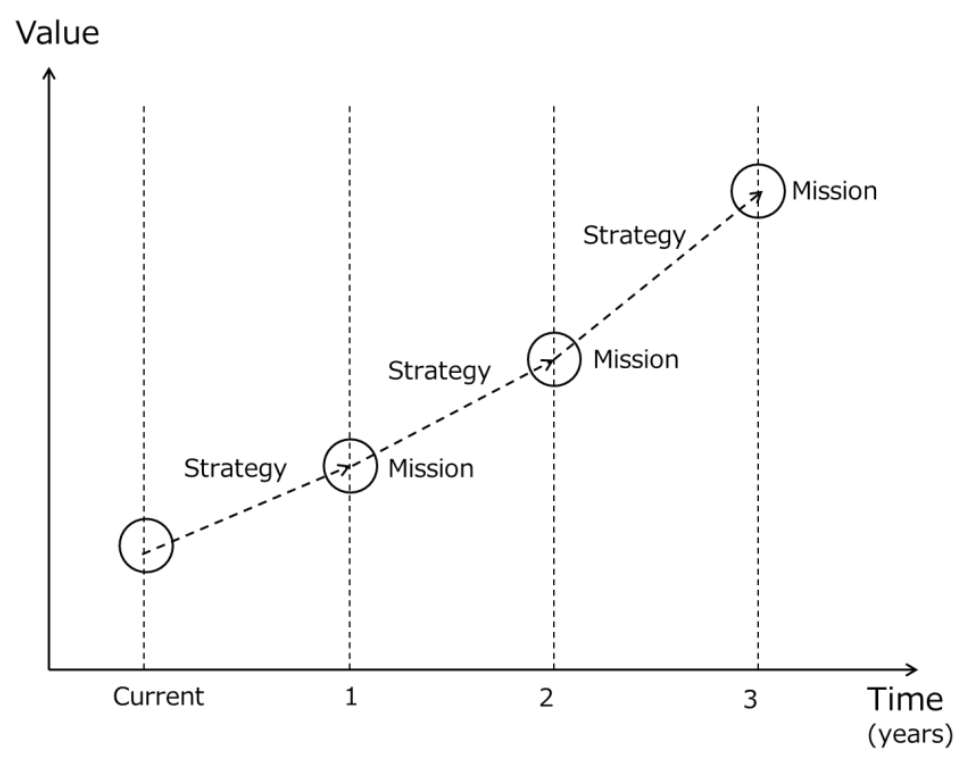

Figure 3 Mentors conceptual overview

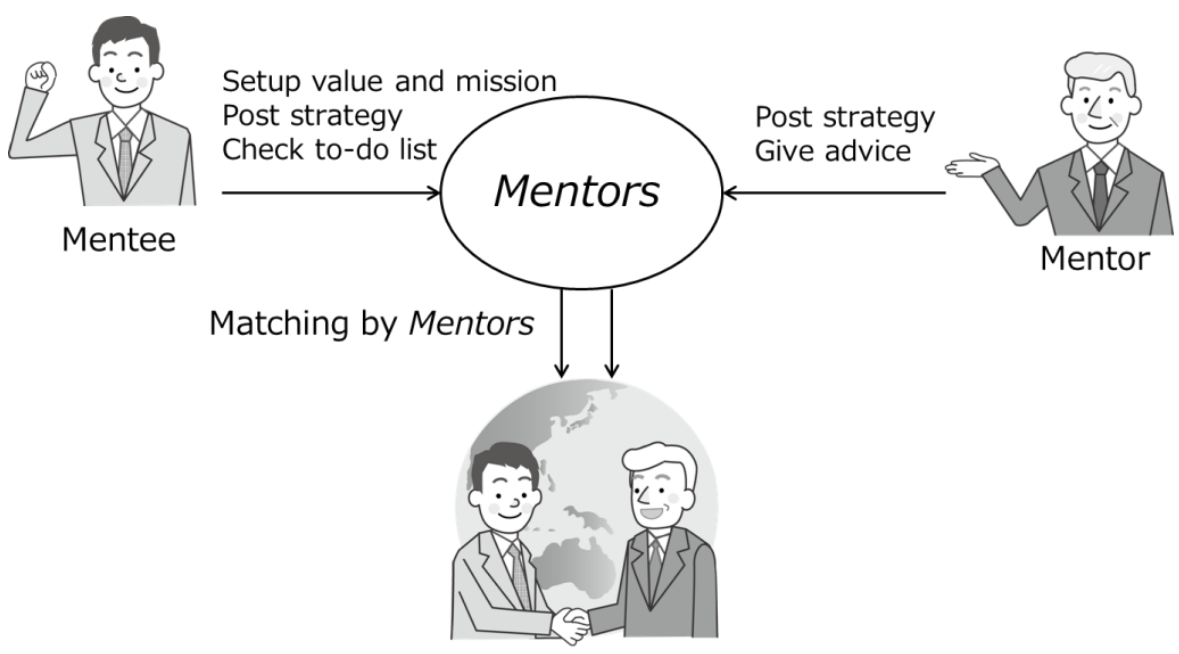

Actual meeting

\section{System Design of Mentors}

In this section, we describe the system design of Mentors. The functions of Mentors are as follows.

- Profile: Includes values, mission, and strategies

Link to social media account (Twitter, Facebook, LinkedIn)

Each user can browse other users' profiles 
- Follow: Watching mentee and mentor

Mentees learn from their role model's activities and way of thinking

Mentors observe the activities of the mentees

- Strategy post: Post a strategy for each mission

- Strategy check: Check off to-do list items as they are completed

- Search: Search for user name, values, and missions

Through the Profile function, a user can confirm his/her values, missions, and strategies. The mentee's own vision and mission can be updated. Furthermore, links to the user's other social media accounts can provide a good general profile of the mentee. A user can become familiar with personal interests, relationships with friends, as well as career and referral information by reading Twitter, Facebook, and LinkedIn, respectively. The "follow" function resembles the "follow" relationship in Twitter; through this function, the mentor can advise the mentee and check that the mentee's strategies are on course. The mentee learns from the activities and thinking of his/her mentor. The "strategy" function is the main function of Mentors, and this is the function that is expected to be used most frequently. Any user can post a strategy for each mission and the format is similar to the comments function on a Facebook post. The mentee chooses an item on a to-do list from a posted strategy. After the to-do list item is completed, the mentee checks it off. From this function, the degree of mission achievement can be evaluated. Using the "search" function, a user can search for other users by user name, values, or mission. When you find someone you are interested in, you can follow him or her.

Mentors has been developed with Ruby on Rails (web application framework). A screenshot of a sample profile after login is shown in Figure 4. This is main screen of Mentors. A user's values, mission, and strategies can be confirmed. In future papers, we will report the details about the system architecture.

\section{Figure 4 Profile Page Screenshot}

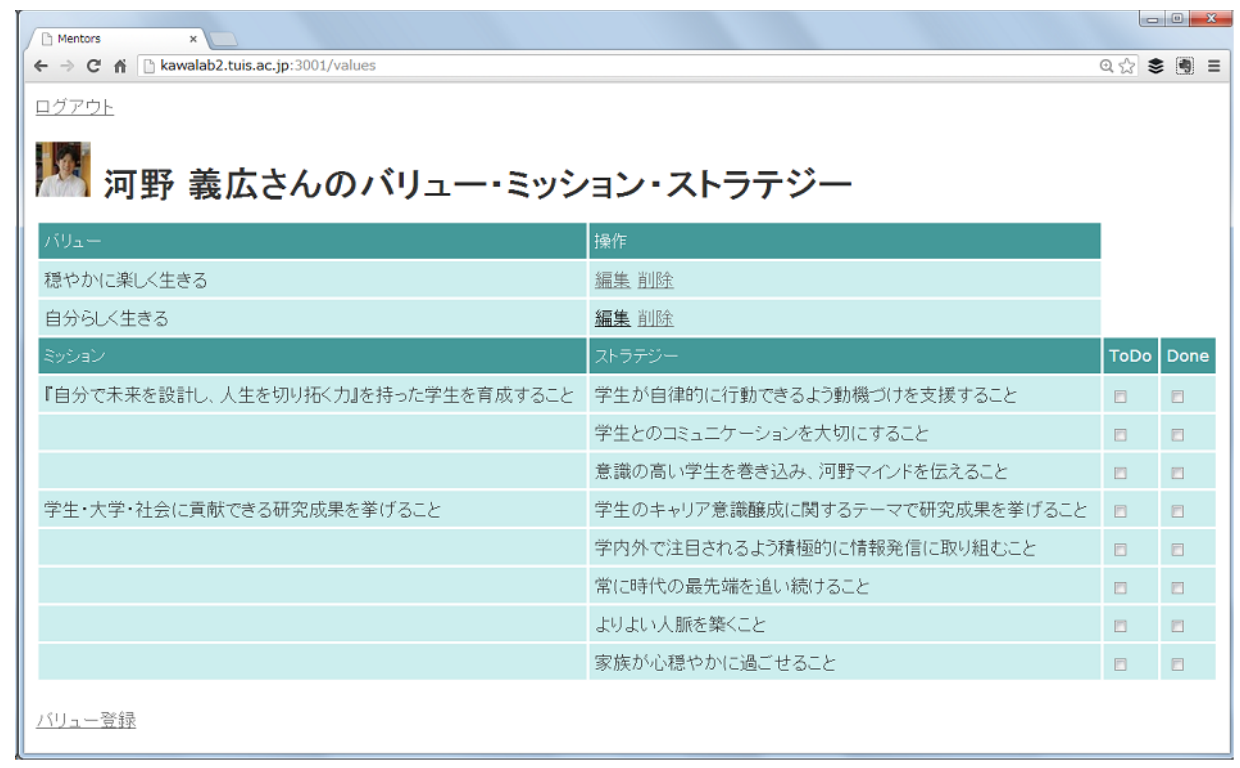

\section{Conclusion}

We propose Mentors, a personal branding support service for university students. The main concept behind Mentors is "Everyone has the face of both a mentor and mentee." The most 
widely used function is sharing components of one's self-analysis in designing one's life, that is, values, mission, and strategies.

Our goal in the future is to launch Mentors. At the present time, we are planning continual observation of student behavior, modelling to find suitable social media for each person, and pilot evaluating Mentors.

\section{References}

Eccles, J. and Wigfield, A. 1985. "Teacher expectancies and student motivation.” In. J. B. Gusek (Ed.), Teacher Expectancies. Hillsdale, N.J. and Erlbaum, L., pp.185-226.

Eccles, J. and Wigfield, A. 2002. "Motivational Beliefs, Value, And Goals." Annual Reviews, Psychology, 53:109-132.

Facebook, https://facebook.com/.

Forkwell, https://forkwell.com/.

Hanzawa, R. 2011. "Daigakusei-no manabi to kyaria ishiki no hattatsu: Daigaku-de-no manabi ni yoru hattatsu-o zentei toshita kyaria kenkyü to iu shiten" ["Studies and Career Development in Undergraduates: A View of Career Research through Studies at University"]. How to Commit to Youth Who Create Their Own Future (Special Issue), Shinri kagaku [Psychological Science] (Japanese Research Association of Psychological Science), 32(1), 22-29.

Japan Center for Economic Research. 2011. "3-nen inai no sōki risshokuritsu 3-wari-no shōgeki: gakusei, kigyō, söhö-ni tadai-na kosuto" ["The shock of 30 percent early unemployment rate for less than three years"]. Available at http://www.jcer.or.jp/report/econ100/pdf/econ100bangai20110715.pdf (in Japanese). Access date: May 10, 2013.

Kawano, Y., Obu, Y., Kishimoto, Y., Yamaguchi, T., Nunohiro, E., and Yonekura, T., 2012. "Personal Branding for University Students through the Practical Use of Social Media." WSSM-2012 (The 1st International Workshop on Web Services and Social Media in conjunction with the 15th International Conference on NBiS-2012). September 2012.

Kawano, Y., Miya, T., Furuya, N., and Obu, Y., 2013. "Education in Social Media Literacy for High School Students in Social Media Times," AROB 18, 2013 (International Symposium on Artificial Life and Robotics). February 2013.

Lent, R. W., Brown, S. D., and Hackett, G., 2002. "Social cognitive career theory," In D. Brown, (Ed.), Career Choice and Development. San Francisco, CA: Wiley. pp. 255311.

LinkedIn, http://www.linkedin.com/.

Ministry of Education, Culture, Sports, Science and Technology (MEXT). 2011. Kongo no gakkō ni okeru kyaria kyōiku shokugyō kyōiku no arikata ni tsuite [The Future of Career and Employment Education in Schools]. Tokyo: Gyōsei.

Ohmoto, T., 2011. Social medeia jissen no sho [Practial Social Media]. Ric Telecom, June 2011.

Perry, D., 2012. "Facebook Now Reaches More than Half of All Internet Users." Tom's Guide, Available at http://www.tomsguide.com/us/facebook-traffic-google-statisticsvisits,news-14070.html. Access date: August 9, 2013.

Peters, T., 1997. "The Brand Called You” August 1997. Available at http://www.fastcompany.com/magazine/10/brandyou.html. Access date: May 10, 2013

Tsubota, K. 2008. Rikei no tame-no jinsei sekkei gaido [Your Guide to Life Planning Natural Sciences]. Tokyo: Kodansha. 
Twitter, http://twitter.com/.

Wantedly, https://www.wantedly.com/.

Wetsch, L. 2011., "Personal Branding with Social Media; An Essential Application of Direct Marketing Skills for Today's Students," Direct/Interactive Marketing Research Summit, October 2011. 